\title{
BIOMECHANICAL EVALUATION OF INTERBODY DEVICES BY USING MECHANICAL COMPRESSIVE TEST: PEEK SPACERS VERSUS PMMA CEMENT SPACERS
}

Márta Kurutz ${ }^{1}$, Tibor Csákány ${ }^{2}$, Péter Varga ${ }^{3}$, Péter Pál Varga ${ }^{2}$

${ }^{1}$ Budapest University of Technology and Economics

${ }^{2}$ National Center for Spinal Disorders

3Julius Wolff Institute and Berlin-Brandenburg School for Regenerative Therapies, Charitè -

Universitätsmedizin

keurutym@eik.bme.bu

\begin{abstract}
If spine degenerations are accompanied by osteoporosis, the traditional PEEK spacers can strongly subside into the irregularly deformed endplates and vertebrae following surgical stabilization. To avoid implant subsidence, a new technique is developed where bone cement is applied as interbody device along the vertebra-implant interface. In this study, the mechanical comparison of the traditional PEEK and the new PMMA cement spacers are presented based on uniaxial compression tests. It was concluded that in osteoporotic spine the cement spacers provide better contact along the irregularly deformed endplates, and stronger vertebra-implant interface leading to enhanced stability of lumbar interbody fixation. In the case of PMMA cages, the failure deformation of segments is almost the half of that of the PEEK spacers, while the stiffness of them is more than two times larger. In strongly osteoporotic cases, a more evenly distributed cement pattern results in smaller stress concentrations and greater strength which may decrease the risk of subsidence.
\end{abstract}

Keywords: interbody devices, PEEK spacer, PMMA bone cement spacer, vertebra-implant interface, device subsidence, failure load, stiffness

\section{Introduction}

During surgical stabilization of spine the degeneration of the disc is often accompanied by osteoporosis of vertebrae. In this case inserting the interbody devices, the traditional spacers into the intervertebral space is very difficult due to the irregularly deformed, weakened osteoporotic endplates of vertebrae, moreover, implant subsidence reduces the strength of the joint and yield further complications. ${ }^{1-5}$ To avoid implant subsidence, the strength of the vertebra-device interface must be increased. According to a new method developed in the National Center for Spinal Disorders in Budapest, instead of traditional spacers, bone cement is applied as interbody device at a certain part of the removed disc, while the other part of the removed disc is filled up by bone graft. ${ }^{6-7}$ The benefit of the new method of using PMMA cement spacers is the larger and more perfect contact between the cement and the irregular surfaces of the endplates, obtaining a more even load transfer along the vertebra-implant interface and decreasing the extreme stress distribution and stress peaks due to the subsidence or penetration of the traditional spacers into the osteoporotic vertebrae.

A better understanding the reason of interbody device subsidence is necessary in order to avoid the problem effectively. ${ }^{5}$ The goal of this work is to compare the mechanical characteristics: 
strength, stiffness and deformability of lumbar motion segments stabilized by traditional PEEK and PMMA cement spacers (without posterior instrumentation), by using uniaxial compression tests. Parallel, we have developed the quantitative computed tomography QCT-based patientspecific nonlinear finite element models of each test specimen to analyze the vertebra-implant interface and the elastic-plastic damage process of the vertebral internal cancellous bone, local and global failure of the motion segment. The results of this part of research and the comparison of the results of mechanical tests and numerical simulations are detailed in other papers.

\section{Methods}

The specimens were prepared in the National Center for Spinal Disorders in Budapest, and the compression tests were executed in the laboratory of the Biomechanical Research Centre of the Budapest University of Technology and Economics.

To analyze the mechanical behaviour of the bone-spacer interface and the cancellous bone inside the vertebrae, posterior instrumentation screw structures have not been applied for the specimens. ${ }^{1}$ For traditional spacer, the polyether ether ketone (PEEK) thermoplastic spacers, while for cement spacer the polymethylmethacrylate (PMMA) bone cement spacers were applied, equally without posterior instrumentation. ${ }^{1}$

At present, for the specimens 16 cadaveric lumbar motion segments were extracted from 8 human lumbar spines (spine/level/gender/age/BMI/): A/L1-4/M/63/24,5/; B/L14/M/52/27,1/; C/L1-4/F/79/24,2/; D/L1-4/M/64/24,5/; E/L1-4/F/88/28,6/; F/L14/F/88/24,2/; G/L1-4/F/75/24,7/; H/L1-4/M/56/24,7/ that were scanned with dual energy $\mathrm{X}$-ray absorptiometry (DEXA) to obtain bone mineral density (BMD), T-score and Z-score.

The 16 motion segments were divided into 2 groups: (1) fixation with PEEK spacers and (2) fixation with PMMA cement cages. In the PMMA group, all possible free places of the intervertebral space were filled in by the injected cement. No further filling material or bone debris was used for the present experiments. The specimens of both groups were embedded parallel by equally about $10 \mathrm{~mm}$ thick PMMA plastic discs around the inferior and superior endplates of the inferior and superior vertebrae, respectively.

Then the specimens were scanned individually with a high-resolution quantitative computed tomography (QCT) system (Hitachi Presto, Hitachi Medical Corporation, Tokyo, Japan) to provide 3D density maps of the specimens and bone quality. Vertebral heights, central and subcortical cross sectional areas, central and subcortical CT grey values were measured on QCT images. The CT scanning was performed for each specimen three times, before and after operation of segments and after the mechanical test. Since the PMMA embedding of specimens were transparent in $\mathrm{CT}$, to distinguish correctly the bone and embedding, the upper and lower surfaces of embeddings were marked by glass pearls. The specimens were stored at $-200 \mathrm{C}$ and were thawed at room temperature 4-6 hours before testing.

Table $1 a$ illustrates the data of patients and pre-operated specimens, Table $1 b$ the data of bone quality of specimens. 


\begin{tabular}{|c|c|c|c|c|c|c|c|c|c|c|}
\hline \multirow[t]{2}{*}{$\begin{array}{l}\text { Cage } \\
\text { type }\end{array}$} & \multirow[t]{2}{*}{$\begin{array}{l}\text { Speci } \\
\text { men }\end{array}$} & \multirow[t]{2}{*}{$\begin{array}{l}\text { Age } \\
(\mathrm{yrs})\end{array}$} & \multirow[t]{2}{*}{ Sex } & \multirow[t]{2}{*}{$\begin{array}{c}\text { BMI } \\
\left(\mathrm{kg} / \mathrm{m}^{2}\right)\end{array}$} & \multicolumn{2}{|c|}{$\begin{array}{l}\text { Height } \\
(\mathrm{mm})\end{array}$} & \multicolumn{4}{|c|}{$\begin{array}{c}\text { Cross Sectional Area } \\
\left(\mathrm{mm}^{2}\right)\end{array}$} \\
\hline & & & & & superior & inferior & $\begin{array}{c}\text { superior } \\
\text { central }\end{array}$ & \begin{tabular}{|c|} 
superior \\
subcort
\end{tabular} & \begin{tabular}{|c|} 
inferior \\
central
\end{tabular} & $\begin{array}{l}\text { inferior } \\
\text { subcort }\end{array}$ \\
\hline \multicolumn{11}{|l|}{ PMMA } \\
\hline PMMA-1 & G/L1-2 & 75 & $\mathrm{~F}$ & 31.2 & 22.40 & 23.90 & 724 & 1011 & 715 & 1115 \\
\hline PMMA-2 & B/L3-4 & 52 & $\bar{M}$ & 27.1 & 26.70 & 27.55 & 896 & 1178 & 1002 & 1238 \\
\hline PMMA-3 & A/L1-2 & 63 & M & 24.5 & 24.70 & 24.95 & 651 & 952 & 690 & 978 \\
\hline $\begin{array}{l}\text { PMMA-4 } \\
\end{array}$ & B/L1-2 & 52 & $\mathrm{M}$ & 27.1 & 26.35 & 26.20 & 683 & 871 & 712 & 896 \\
\hline PMMA-5 & F/L1-2 & 88 & F & 24.2 & 26.10 & 26.70 & 814 & 1053 & 877 & 1133 \\
\hline PMMA-6 & F/L3-4 & 88 & $\mathrm{~F}$ & 24.2 & 28.80 & 28.65 & 907 & 1174 & 981 & 1219 \\
\hline mean & & 69.7 & & 26.4 & 25.8 & 26.3 & 779 & 1040 & 830 & 1097 \\
\hline SD & & 16.5 & & 2.73 & 2.1 & 1.7 & 109 & 122 & 142 & 135 \\
\hline \multicolumn{11}{|l|}{ PEEK } \\
\hline PEEK-1 & C/L3-4 & 79 & $\mathrm{~F}$ & 24.2 & 26.60 & 26.90 & 1071 & 1304 & 1145 & 1569 \\
\hline PEEK-2 & H/L1-2 & 56 & M & 24.7 & 28.50 & 30.10 & 1049 & 1573 & 1181 & 1564 \\
\hline $\begin{array}{l}\text { PEEK-3 } \\
\end{array}$ & H/L3-4 & 56 & $\mathrm{M}$ & 24.7 & 28.60 & 29.25 & 1349 & 1796 & 1344 & 1728 \\
\hline $\begin{array}{l}\text { PEEK-4 } \\
\end{array}$ & D/L1-2 & 64 & $\mathrm{M}$ & 24.5 & 28.73 & 28.50 & 1086 & 1366 & 1152 & 1475 \\
\hline PEEK-5 & D/L3-4 & 64 & $\mathrm{M}$ & 24.5 & 28.00 & 26.40 & 1224 & 1587 & 1283 & 1549 \\
\hline PEEK-6 & E/L1-2 & 88 & F & 28.6 & 24.91 & 25.71 & 825 & 1005 & 929 & 1127 \\
\hline mean & & 67.8 & & 25.2 & 27.6 & 27.8 & 1101 & 1439 & 1172 & 1502 \\
\hline SD & & 13.0 & & 1.68 & 1.5 & 1.7 & 177 & 275 & 143 & 201 \\
\hline
\end{tabular}

Table 1a: Data of patients and geometry of pre-operated specimens

\begin{tabular}{|c|c|c|c|c|c|c|c|c|c|}
\hline $\begin{array}{c}\text { Cage } \\
\text { type }\end{array}$ & $\begin{array}{c}\text { Speci- } \\
\text { men }\end{array}$ & \multicolumn{2}{|c|}{$\begin{array}{c}\text { BMD } \\
\left(\mathrm{g} / \mathrm{cm}^{2}\right)\end{array}$} & \multicolumn{2}{c|}{ T-score } & \multicolumn{4}{c|}{ CT-grey } \\
\hline & & superior & inferior & superior & inferior & $\begin{array}{c}\text { superior } \\
\text { central }\end{array}$ & $\begin{array}{c}\text { superior } \\
\text { subcortical }\end{array}$ & $\begin{array}{c}\text { inferior } \\
\text { central }\end{array}$ & $\begin{array}{c}\text { inferior } \\
\text { subcortical }\end{array}$ \\
\hline PMMA & & & & & & & & & \\
\hline PMMA-1 & G/L1-2 & 0.606 & 0.620 & -4.4 & -4.8 & 76 & 123 & 85 & 94 \\
\hline PMMA-2 & B/L3-4 & 0.975 & 0.934 & -2.2 & -2.6 & 196 & 171 & 186 & 120 \\
\hline PMMA-3 & A/L1-2 & 0.789 & 0.828 & -3.1 & -3.4 & 137 & 157 & 90 & 132 \\
\hline PMMA-4 & B/L1-2 & 0.764 & 0.900 & -3.3 & -2.8 & 141 & 183 & 133 & 149 \\
\hline PMMA-5 & F/L1-2 & 0.620 & 0.659 & -4.3 & -4.5 & 73 & 107 & 70 & 102 \\
\hline PMMA-6 & F/L3-4 & 0.721 & 0.768 & -4.0 & -3.6 & 106 & 136 & 105 & 96 \\
\hline mean/ & & $\mathbf{0 . 7 4 6}$ & $\mathbf{0 . 7 8 5}$ & $\mathbf{- 3 . 6}$ & $\mathbf{- 3 . 6}$ & $\mathbf{1 2 2}$ & $\mathbf{1 4 6}$ & $\mathbf{1 1 2}$ & $\mathbf{1 1 6}$ \\
\hline SD & & $\mathbf{0 . 1 3 5}$ & $\mathbf{0 . 1 2 7}$ & $\mathbf{0 . 8}$ & $\mathbf{0 . 9}$ & $\mathbf{4 7}$ & $\mathbf{2 9}$ & $\mathbf{4 2}$ & $\mathbf{2 2}$ \\
\hline PEEK & & & & & & & & & \\
\hline PEEK-1 & C/L3-4 & 0.676 & 0.670 & -4.4 & -4.4 & 50 & 78 & 29 & 94 \\
\hline PEEK-2 & H/L1-2 & 0.834 & 0.919 & -2.7 & -2.7 & 117 & 174 & 104 & 166 \\
\hline PEEK-3 & H/L3-4 & 0.892 & 0.863 & -2.9 & -3.1 & 141 & 219 & 152 & 194 \\
\hline PEEK-4 & D/L1-2 & 0.828 & 0.828 & -3.4 & -3.4 & 109 & 110 & 80 & 109 \\
\hline PEEK-5 & D/L3-4 & 0.913 & 0.888 & -2.7 & -2.9 & 79 & 134 & 86 & 101 \\
\hline PEEK-6 & E/L1-2 & 0.751 & 0.827 & -3.2 & -3.1 & 107 & 124 & 84 & 123 \\
\hline mean & & $\mathbf{0 . 8 1 6}$ & $\mathbf{0 . 8 3 3}$ & $\mathbf{- 3 . 2}$ & $\mathbf{- 3 . 3}$ & $\mathbf{1 0 1}$ & $\mathbf{1 4 0}$ & $\mathbf{8 9}$ & $\mathbf{1 3 1}$ \\
\hline SD & & $\mathbf{0 . 0 8 9}$ & $\mathbf{0 . 0 8 7}$ & $\mathbf{0 . 6}$ & $\mathbf{0 . 6}$ & $\mathbf{3 2}$ & $\mathbf{5 0}$ & $\mathbf{4 0}$ & $\mathbf{4 0}$ \\
\hline
\end{tabular}

Table 1b: Bone quality data of pre-operated specimens 
The compressive mechanical test was executed by using a servohydraulic universal testing machine (Instron 8870 series). Axial compressive displacement load was applied at a rate of 0.5 $\mathrm{mm} / \mathrm{min}$ speed, to the limit of $20 \%$ decrease of the compressive force or $20 \%$ of compressive strain of the specimen. Axial compressive force and displacement were measured and the relating force-displacement curve was plotted. Failure loads, failure displacements and structural stiffnesses were extracted from the load-displacement curves. Failure load was the maximum load before the gradient of the curve changed from positive to negative, whereas stiffness was the slope of the linear portion of the load-displacement curve before failure occurred. Failure stresses were calculated along the central and subcortical cross sections of both the superior and inferior vertebrae, dividing the failure load by the relating cross sectional area of vertebra.

At present, the results of the mechanical tests is based on $2 \times 6$ specimens from the $2 \times 8$ ones, since the load-deflection curve of two specimens from both groups were invaluable.

\section{Results}

In Figure 1 the typical load-displacement curves of specimens stabilized by PEEK and PMMA cement cages are illustrated, while the relating numerical results are seen in Table $2 a$ and $2 b$.

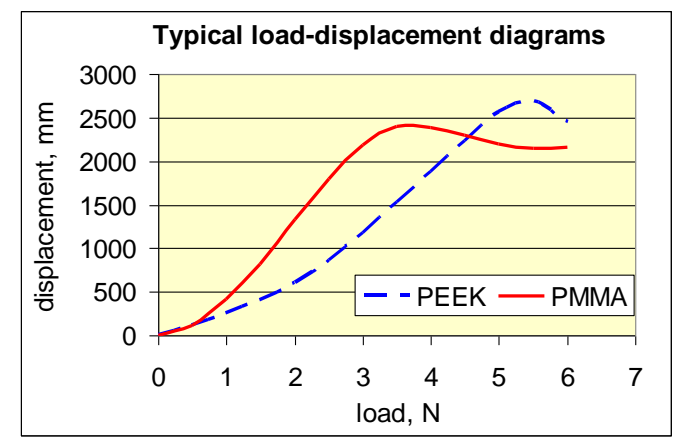

Figure 1. Typical load-displacement diagram of segments with PEEK and PMMA cement spacers

The mean failure load, elastic stiffness, failure displacement and failure stresses of specimens with PEEK and PMMA cement cages can be seen in Figure 2. Compressive failure load was not significantly affected by the cage types $(\mathrm{P}>0.3)$; it was $9 \%$ smaller in PMMA group in average (Figure 2a). On the contrary, compressive stiffness of segments was significantly affected by fixation devices $(\mathrm{P}<0.002)$ : it was nearly two and a half times larger $(247 \%)$ in the PMMA group than in the PEEK group (Figure 2b). Failure displacements, the shortening of segments in the PMMA group were only the half of that of the PEEK group $(\mathrm{P}<0.0002$, Figure $2 c)$. Central and subcortical failure stresses of upper and lower vertebrae in PMMA group were equally about 25$28 \%$ higher $(\mathrm{P}<0.004)$ since the related central areas of vertebrae were about $27-29 \%$ smaller in this group. In contrast to the PMMA group, the standard deviation of all mechanical parameters (compared to the mean values) was definitely larger in the PEEK group, indicating the higher uncertainty and vulnerability of this kind of fixation. Central and subcortical failure stresses of upper and lower vertebrae in PMMA group were equally about $25-28 \%$ higher since the related central areas were about $27-29 \%$ smaller in this group. 


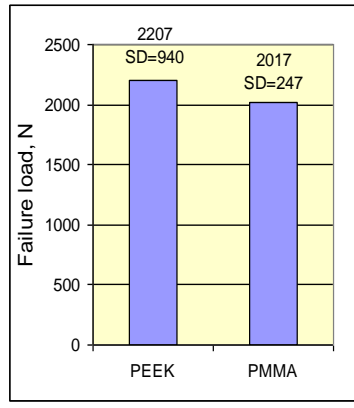

(a)

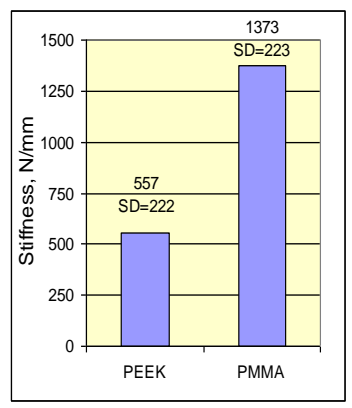

(b)

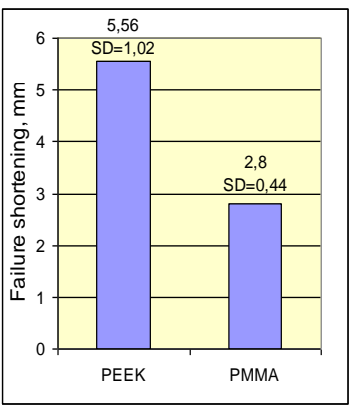

(c)

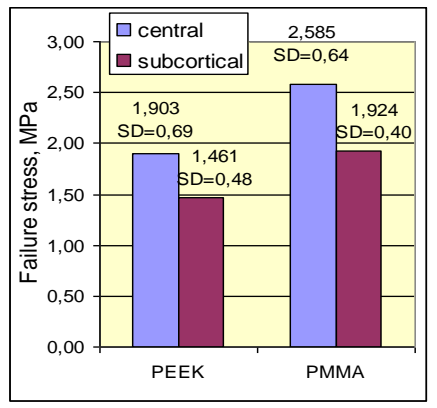

(d)

Figure 2. Mean failure load (a), stiffness (b), failure displacements (c) and failure stresses (d) of segments with PEEK and PMMA cement cages

\begin{tabular}{|r|l|c|c|c|c|c|c|c|c|}
\hline $\begin{array}{c}\text { Type of } \\
\text { spacers }\end{array}$ & Sample & $\begin{array}{c}\text { Failure } \\
\text { load } \\
(\mathrm{N})\end{array}$ & $\begin{array}{c}\text { Stiffness } \\
(\mathrm{N} / \mathrm{mm})\end{array}$ & $\begin{array}{c}\text { Failure } \\
\text { deform. } \\
(\mathrm{mm})\end{array}$ & $\begin{array}{c}\text { Type of } \\
\text { spacers }\end{array}$ & Sample & $\begin{array}{c}\text { Failure } \\
\text { load } \\
(\mathrm{N})\end{array}$ & $\begin{array}{c}\text { Stiffness } \\
(\mathrm{N} / \mathrm{mm})\end{array}$ & $\begin{array}{c}\text { Failure } \\
\text { deform. } \\
(\mathrm{mm})\end{array}$ \\
\hline PMMA & & & & & PEEK & & & & \\
\hline PMMA-1 & G/L1-2 & 2013 & 1460 & 2.52 & PEEK-1 & C/L3-4 & 1400 & 350 & 5.70 \\
\hline PMMA-2 & B/L3-4 & 1630 & 1250 & 2.68 & PEEK-2 & H/L1-2 & 2933 & 770 & 5.00 \\
\hline PMMA-3 & A/L1-2 & 2398 & 1050 & 3.57 & PEEK-3 & H/L3-4 & 3368 & 760 & 6.86 \\
\hline PMMA-4 & B/L1-2 & 1975 & 1410 & 2.70 & PEEK-4 & D/L1-2 & 2687 & 745 & 5.35 \\
\hline PMMA-5 & F/L1-2 & 1984 & 1350 & 3.00 & PEEK-5 & D/L3-4 & 1893 & 390 & 6.42 \\
\hline PMMA-6 & F/L3-4 & 2100 & 1720 & 2.33 & PEEK-6 & E/L1-2 & 958 & 325 & 4.00 \\
\hline mean & & $\mathbf{2 0 1 7}$ & $\mathbf{1 3 7 3}$ & $\mathbf{2 . 8 0}$ & mean & & $\mathbf{2 2 0 7}$ & $\mathbf{5 5 7}$ & $\mathbf{5 . 5 6}$ \\
\hline SD & & $\mathbf{2 4 7}$ & $\mathbf{2 2 3}$ & $\mathbf{0 . 4 4}$ & SD & & $\mathbf{9 4 0}$ & $\mathbf{2 2 2}$ & $\mathbf{1 . 0 2}$ \\
\hline
\end{tabular}

Table 2a. Failure load, stiffness and failure shortening of segments with PMMA and PEEK spacers

\begin{tabular}{|l|l|c|c|c|c|c|c|c|c|c|c|}
\hline $\begin{array}{l}\text { Type of } \\
\text { Spacers }\end{array}$ & Sample & $\begin{array}{c}\text { Stresses } \\
\text { central } \\
\text { superior } \\
(\mathrm{MPa})\end{array}$ & $\begin{array}{c}\text { Stresses } \\
\text { central } \\
\text { inferior } \\
(\mathrm{MPa})\end{array}$ & $\begin{array}{c}\text { trresses } \\
\text { subcort. } \\
\text { superior } \\
(\mathrm{MPa})\end{array}$ & $\begin{array}{c}\text { Stresses } \\
\text { subcort. } \\
\text { inferior } \\
(\mathrm{MPa})\end{array}$ & $\begin{array}{c}\text { Type of } \\
\text { Spacers }\end{array}$ & Sample & $\begin{array}{c}\text { Stresses } \\
\text { central } \\
\text { superior } \\
(\mathrm{MPa})\end{array}$ & $\begin{array}{c}\text { Stresses } \\
\text { central } \\
\text { inferior } \\
(\mathrm{MPa})\end{array}$ & $\begin{array}{c}\text { Stresses } \\
\text { subcort. } \\
\text { superior } \\
(\mathrm{MPa})\end{array}$ & $\begin{array}{c}\text { Stresses } \\
\text { subcort. } \\
\text { inferior } \\
(\mathrm{MPa})\end{array}$ \\
\hline PMMA & & & & & & PEEK & & & & & \\
\hline PMMA-1 & $\mathrm{G} / \mathrm{L} 1-2$ & 2,780 & 2,815 & 1,991 & 1,805 & PEEK-1 & C/L3-4 & 1,307 & 1,223 & 1,074 & 0,892 \\
\hline PMMA-2 & $\mathrm{B} / \mathrm{L} 3-4$ & 1,819 & 1,627 & 1,384 & 1,317 & PEEK-2 & H/L1-2 & 2,796 & 2,483 & 1,865 & 1,875 \\
\hline PMMA-3 & $\mathrm{A} / \mathrm{L} 1-2$ & 3,684 & 3,475 & 2,519 & 2,452 & PEEK-3 & H/L3-4 & 2,497 & 2,506 & 1,875 & 1,949 \\
\hline PMMA-4 & $\mathrm{B} /$ L1-2 & 2,892 & 2,774 & 2,268 & 2,204 & PEEK-4 & D/L1-2 & 2,474 & 2,332 & 1,967 & 1,822 \\
\hline PMMA-5 & F/L1-2 & 2,437 & 2,262 & 1,884 & 1,751 & PEEK-5 & D/L3-4 & 1,547 & 1,475 & 1,193 & 1,222 \\
\hline PMMA-6 & F/L3-4 & 2,315 & 2,141 & 1,789 & 1,723 & PEEK-6 & E/L1-2 & 1,161 & 1,031 & 0,953 & 0,850 \\
\hline mean & & $\mathbf{2 , 6 7 3}$ & $\mathbf{2 , 5 5 9}$ & $\mathbf{1 , 9 7 5}$ & $\mathbf{1 , 8 6 5}$ & mean & & $\mathbf{1 , 9 6 4}$ & $\mathbf{1 , 8 4 2}$ & $\mathbf{1 , 4 8 8}$ & $\mathbf{1 , 4 3 5}$ \\
\hline SD & & $\mathbf{0 , 5 8}$ & $\mathbf{0 , 6 0}$ & $\mathbf{0 , 3 6}$ & $\mathbf{0 , 3 7}$ & SD & & $\mathbf{0 , 7 1}$ & $\mathbf{0 , 6 7}$ & $\mathbf{0 , 4 6}$ & $\mathbf{0 , 5 1}$ \\
\hline
\end{tabular}

Table 2b. Failure stresses in central and subcortical level of vertebrae of segments with PMMA and PEEK spacers 
Correlation between failure load and bone quality can be seen in Figure 3. Correlation of the superior and inferior vertebrae for PMMA and PEEK spacers are shown in Table 3. Surprisingly, while the failure load of PEEK spacers showed a good positive correlation with the bone quality, mainly with CT grey $(\mathrm{R}=0,75)$, and less with BMD $(\mathrm{R}=0,59)$, the PMMA cement specimens showed a poor negative correlation (about $\mathrm{R}=-0,40$ ), as seen in Figures $3 a$ and $3 b$.

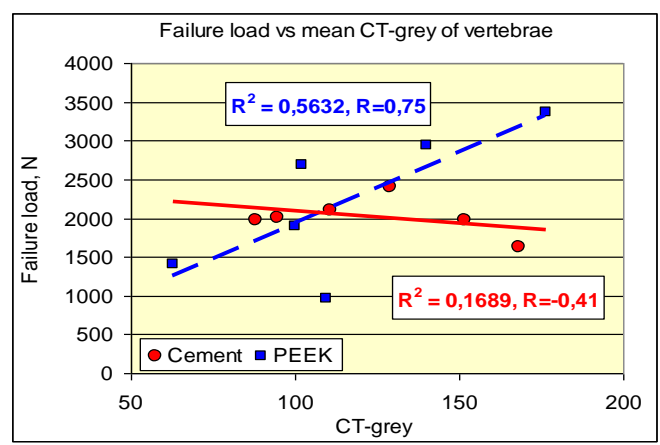

a)

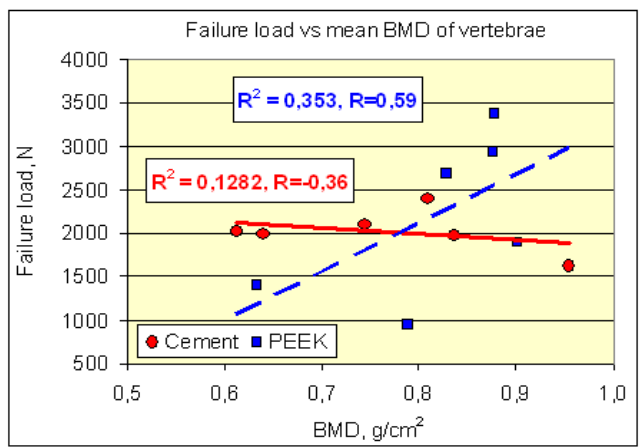

b)

Figure 3. Failure load versus a) mean CT-grey and b) mean BMD of vertebrae

\begin{tabular}{|c|c|c|c|c|c|c|c|c|c|c|}
\hline $\begin{array}{c}\text { Failure } \\
\text { load }\end{array}$ & \multicolumn{9}{|c|}{ CT-grey } & \multicolumn{3}{c|}{ BMD } \\
\hline $\begin{array}{c}\text { Cage } \\
\text { Type }\end{array}$ & $\begin{array}{c}\text { central } \\
\text { superior }\end{array}$ & $\begin{array}{c}\text { central } \\
\text { inferior }\end{array}$ & $\begin{array}{c}\text { subcort } \\
\text { superior }\end{array}$ & $\begin{array}{c}\text { subcort } \\
\text { inferior }\end{array}$ & $\begin{array}{c}\text { central } \\
\text { mean }\end{array}$ & $\begin{array}{c}\text { subcort } \\
\text { mean }\end{array}$ & mean & & superior & inferior \\
\hline PMMA & -0.40 & -0.71 & -0.18 & -0.08 & -0.56 & -0.07 & -0.41 & -0.42 & -0.27 & -0.36 \\
\hline PEEK & 0.69 & 0.72 & 0.74 & 0.73 & 0.72 & 0.75 & 0.75 & 0.65 & 0.53 & 0.59 \\
\hline
\end{tabular}

Table 3. Correlation between failure load and bone quality of superior and inferior vertebrae for PMMA and PEEK spacers

However, the failure deformability, the shortening of specimens had practically no correlation with the bone quality at all, neither in the PEEK and nor in the PMMA group, as shown in Figure 4. Correlation between failure deformability and bone quality of the superior and inferior vertebrae for PMMA and PEEK spacers can be seen in Table 4.

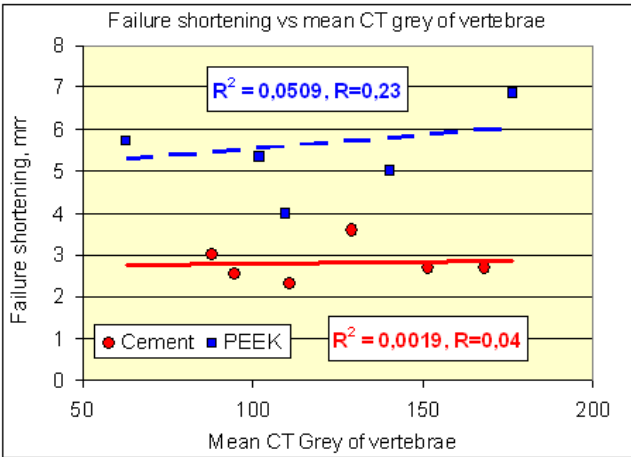

a)

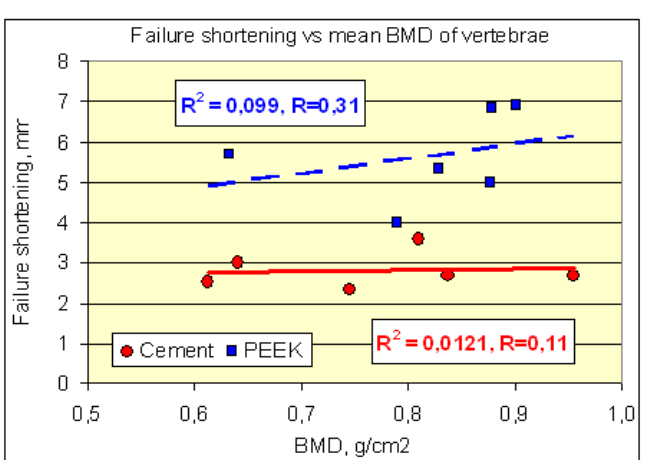

b)

Figure 4. Failure shortening versus a) mean CT-grey and b) mean BMD 


\begin{tabular}{|c|c|c|c|c|c|c|c|c|c|c|}
\hline $\begin{array}{c}\text { Failure } \\
\text { deformation }\end{array}$ & \multicolumn{9}{|c|}{ CT-grey } & \multicolumn{3}{c|}{ BMD } \\
\hline $\begin{array}{c}\text { Cage } \\
\text { Type }\end{array}$ & $\begin{array}{c}\text { central } \\
\text { superior }\end{array}$ & $\begin{array}{c}\text { central } \\
\text { inferior }\end{array}$ & $\begin{array}{c}\text { subcort } \\
\text { superior }\end{array}$ & $\begin{array}{c}\text { subcort } \\
\text { inferior }\end{array}$ & $\begin{array}{c}\text { central } \\
\text { mean }\end{array}$ & $\begin{array}{c}\text { subcort } \\
\text { mean }\end{array}$ & mean & superior & inferior & mean \\
\hline PMMA & 0.11 & -0.28 & 0.08 & 0.44 & -0.07 & 0.24 & 0.04 & 0.10 & 0.12 & 0.11 \\
\hline PEEK & -0.03 & 0.32 & 0.35 & 0.15 & 0.17 & 0.26 & 0.23 & 0.60 & 0.11 & 0.31 \\
\hline
\end{tabular}

Table 4. Correlation between failure shortening and bone quality of superior and inferior vertebrae for PMMA and PEEK spacers

Nevertheless, similar to the failure load was the behaviour of the elastic stiffness that showed a considerable positive correlation with both CT grey $(\mathrm{R}=0,69)$ and BMD $(0,53)$ in PEEK group, and a small negative correlation $(\mathrm{R}=-0,35$ and $\mathrm{R}=-0,36)$ in PMMA group (Figure $5 a, b$ ). Correlation of elastic stiffness with bone quality of the superior and inferior vertebrae for PMMA and PEEK spacers can be seen in Table 5 .

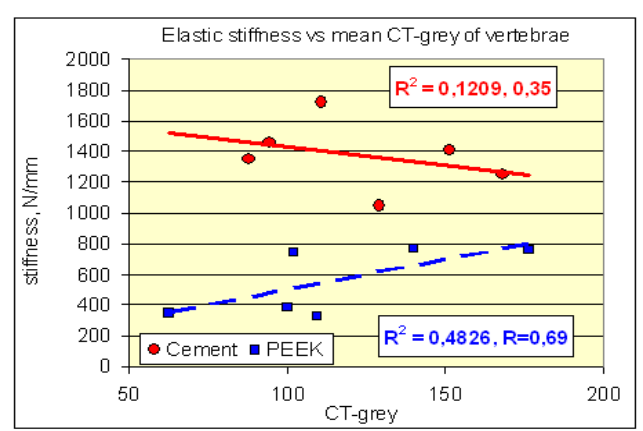

a)

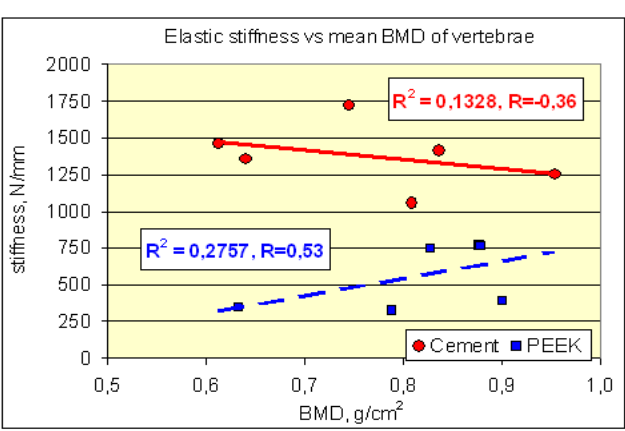

b)

Figure 5. Elastic stiffness versus a) mean CT-grey and b) mean BMD

\begin{tabular}{|c|c|c|c|c|c|c|c|c|c|c|}
\hline $\begin{array}{c}\text { Elastic } \\
\text { stiffness }\end{array}$ & \multicolumn{9}{|c|}{ CT-grey } & \multicolumn{4}{c|}{ BMD } \\
\hline $\begin{array}{c}\text { Cage } \\
\text { Type }\end{array}$ & $\begin{array}{c}\text { central } \\
\text { superior }\end{array}$ & $\begin{array}{c}\text { central } \\
\text { inferior }\end{array}$ & $\begin{array}{c}\text { subcort } \\
\text { superior }\end{array}$ & $\begin{array}{c}\text { subcort } \\
\text { inferior }\end{array}$ & $\begin{array}{c}\text { central } \\
\text { mean }\end{array}$ & $\begin{array}{c}\text { subcort } \\
\text { mean }\end{array}$ & mean & & \\
superior & inferior & mean \\
\hline PMMA & -0.42 & -0.11 & -0.30 & -0.53 & -0.28 & -0.41 & -0.36 & -0.39 & -0.32 & -0.36 \\
\hline PEEK & 0.73 & 0.64 & 0.64 & 0.69 & 0.70 & 0.75 & 0.69 & 0.52 & 0.51 & 0.53 \\
\hline
\end{tabular}

Table 5. Correlation between elastic stiffness and bone quality of superior and inferior vertebrae for PMMA and PEEK spacers

Also similar was the behaviour of the central and subcortical compressive stresses both in the superior and inferior vertebra in PEEK group, having a considerable positive correlation with both CT grey (mean $\mathrm{R}=0,69$ ) and BMD (mean $\mathrm{R}=0,57$ ), seen in Figure $6 a$ and Table 6 . However, in the PMMA group, in the central region a small negative, while in the subcortical region a small positive correlation was with $\mathrm{CT}$ grey (mean $\mathrm{R}=-0,40$ and $\mathrm{R}=033$ resp.), and equally a small negative correlation was in both region with $\mathrm{BMD}$ (mean $\mathrm{R}=-0,21$ ) (Figure 5 b). 


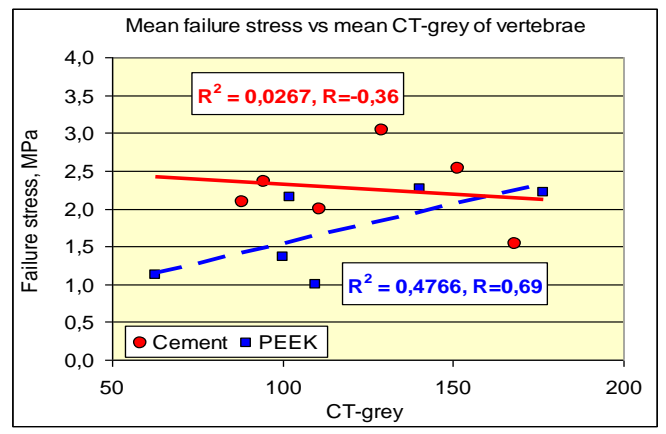

a)

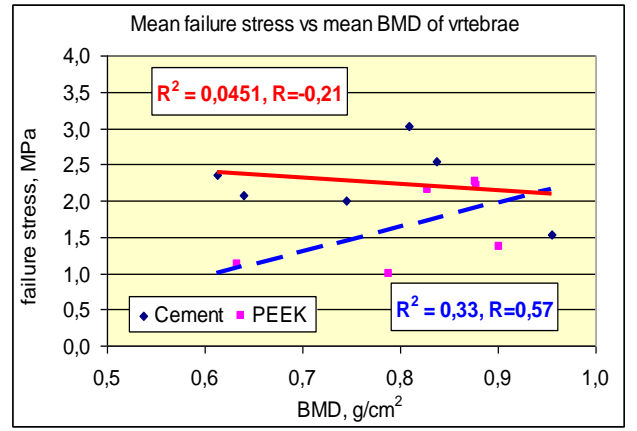

b)

Figure 6. Mean central failure stresses versus a) mean CT-grey and b) mean BMD

\begin{tabular}{|c|c|c|c|c|c|c|c|c|c|c|}
\hline $\begin{array}{c}\text { Failure } \\
\text { stresses }\end{array}$ & \multicolumn{9}{|c|}{ CT-grey } & \multicolumn{3}{c|}{ BMD } \\
\hline $\begin{array}{c}\text { Cage } \\
\text { Type }\end{array}$ & $\begin{array}{c}\text { central } \\
\text { superior }\end{array}$ & $\begin{array}{c}\text { central } \\
\text { inferior }\end{array}$ & $\begin{array}{c}\text { subcort } \\
\text { superior }\end{array}$ & $\begin{array}{c}\text { subcort } \\
\text { inferior }\end{array}$ & $\begin{array}{c}\text { central } \\
\text { mean }\end{array}$ & $\begin{array}{c}\text { subcort } \\
\text { mean }\end{array}$ & mean & $\begin{array}{c}\text { central } \\
\text { mean }\end{array}$ & $\begin{array}{c}\text { subcort } \\
\text { mean }\end{array}$ & mean \\
\hline PMMA & -0.22 & -0.56 & 0.12 & 0.55 & -0.40 & 0.33 & -0.36 & -0.24 & -0.16 & -0.21 \\
\hline PEEK & 0.68 & 0.67 & 0.56 & 0.69 & 0.68 & 0.65 & 0.69 & 0.57 & 0.58 & 0.57 \\
\hline
\end{tabular}

Table 6. Correlation between failure stresses and bone quality of superior and inferior vertebrae for PMMA and PEEK spacers

As seen in Figures $7 a$ and $7 b$, between the failure load and the central and subcortical cross sectional areas of vertebrae there was a strong positive correlation $(R=0,71$ and $R=0,81$, respectively) for the PEEK group, mainly for the subcortical areas, both for the superior and inferior vertebra; while in PMMA group there was a modest negative correlation, better for central $(R=-0,59)$ than for the subcortical areas $(-0,48)$.

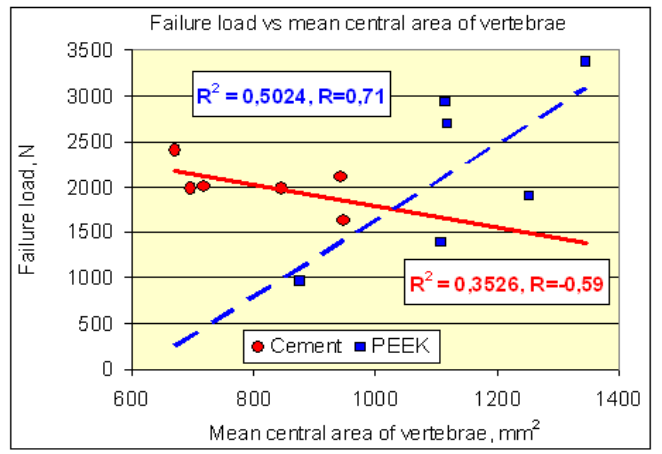

a)

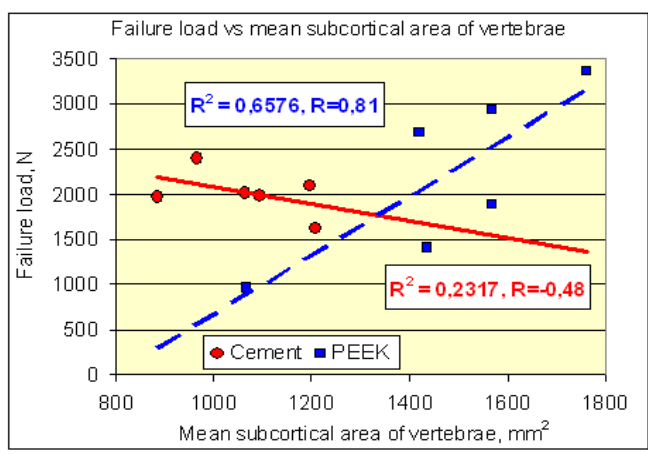

b)

Figure 7. Failure load versus a) central and b) subcortical cross section area of vertebrae

Similarly, between the failure shortening and vertebral areas a strong positive correlation was found for the PEEK group, mainly for the central $(\mathrm{R}=0,95)$ than for the subcortical areas $(\mathrm{R}=0,84)$; however, the PMMA group attested a modest negative correlation $(\mathrm{R}=-0,52$ and $\mathrm{R}=-$ $0,47)$, seen in Figures $8 a$ and $8 b$, respectively. 


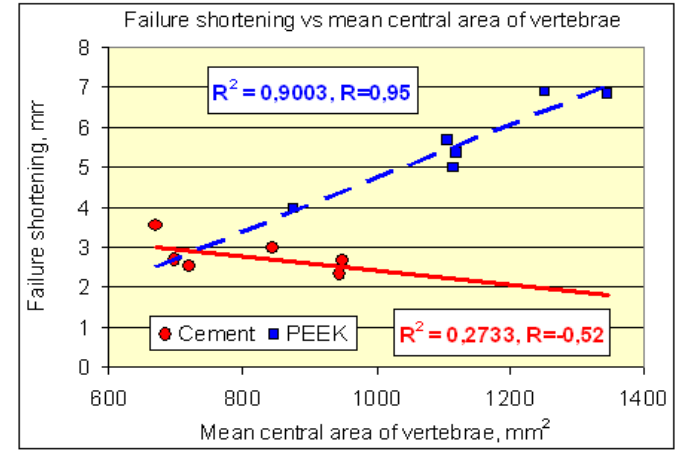

a)

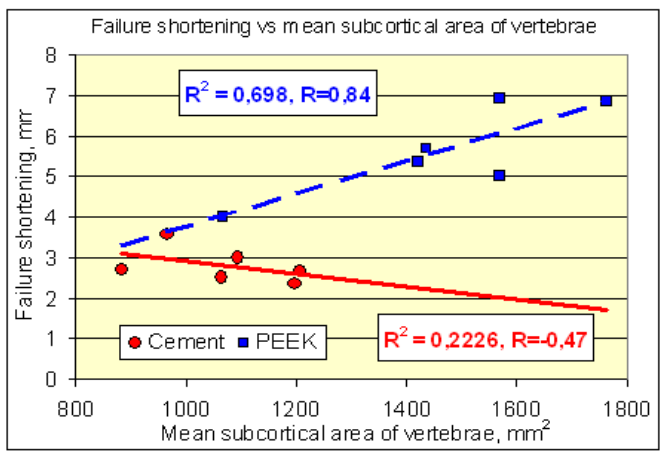

b)

Figure 8. Failure shortening versus a) central and b) subcortical cross section area of vertebrae

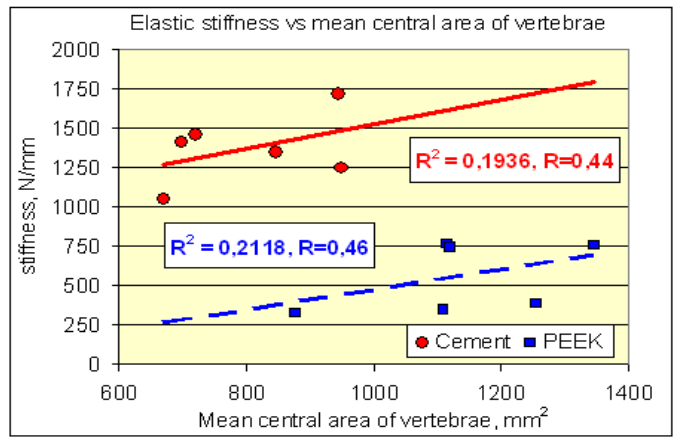

a)

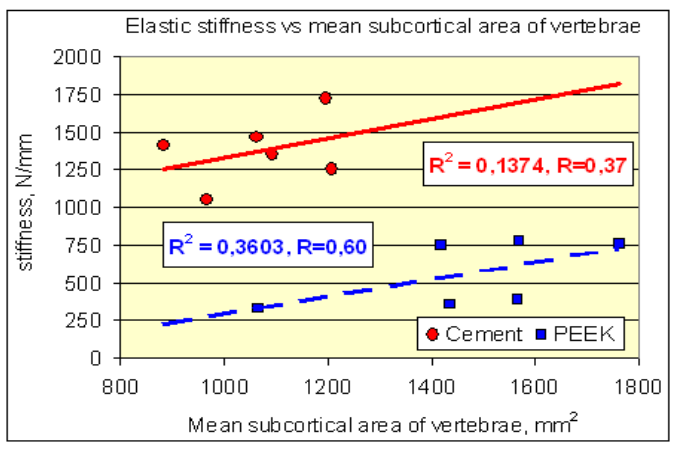

b)

Figure 9. Elastic stiffness versus a) central and b) subcortical cross section area of vertebrae

Between the elastic stiffness and the central cross sectional areas of vertebrae a modest positive correlation was observed for both type of cages (about $\mathrm{R}=0,45$ ), however, with the subcortical areas the PEEK spacers showed a better correlation $(\mathrm{R}=0,60)$ than the PMMA spacers $(\mathrm{R}=0,37)$ as seen in Figures $9 a$ and $9 b$.

\section{Discussion}

In this work novel PMMA cement cages were compared with standard PEEK spacers using axial compressive test. The specimens were stabilized without instrumentation. Jost et al. ${ }^{1}$ proved by using mechanical compressive tests for comparing several interbody cages that the posterior instrumentation has no significant effect on the load bearing of stabilized segments.

The average failure loads of $2017 \mathrm{~N}$ and $2207 \mathrm{~N}$ for PMMA and PEEK cages in this study (Table 2) were comparable to the values reported in previous literature, ${ }^{5,8-10}$ however, there are considerable differences in the failure loads obtained by different embedding methods of the specimens. The average segmental stiffness of $557 \mathrm{~N} / \mathrm{mm}$ of group of PEEK spacers and the higher stiffness of $1373 \mathrm{~N} / \mathrm{mm}$ in group of novel PMMA cement spacers compared well with the values reported in. ${ }^{5,8,10}$ The average failure displacements of 5,56 $\mathrm{mm}$ of PEEK group and 2.80 mm of PMMA group are in the ranges reported in. ${ }^{1,10}$ 
Surprisingly, the load bearing capacity of segments is inversely proportional with the bone quality of vertebrae in the case of PMMA cages, mainly centrally, while the load bearing of PEEK spacers is strongly related to the bone quality, mainly subcortically (Figure 3 and Table 3). In the latter case the reason is that the contact of PEEK spacers needs strong subcortical bone due to the concentrated force-like load transfer along the vertebra-device interface, since in order to avoid implant subsidence or, equivalently, to obtain higher load bearing, the strength of the vertebra-device interface must exceed the applied loads. Previous experimental results of compressive test ${ }^{10}$ suggest that the local trabecular structure beneath the endplate is an important component in the use of mesh cage. According to, ${ }^{5}$ interbody device subsidence results from failure at the bone-implant interface rather than failure of the implant in itself. Similarly, higher failure loads have been reported for higher bone densities. ${ }^{1,10}$ Unfortunately, even the strong interface is missing particularly in osteoporotic patients. In an osteoporotic spine, the same stability cannot be expected from the mesh cage as in a normal spine. ${ }^{10}$ Several reports suggest that the stability of the cage in reconstructive surgery can not be guaranteed for strongly osteoporotic spine. ${ }^{1-2,5-6,10} \operatorname{In}^{13}$ most of the fiber mesh implants subsided into the vertebral cancellous bone at compressive failure, suggesting that significant osteoporosis may be a contraindication for posterior lumbar interbody fusion..$^{10}$

However, by injecting PMMA cement into the intervertebral space, the cement can penetrate into the gaps of osteoporotic vertebral bone providing a smooth, perfect and strong vertebra-device interface yielding higher strength, load bearing and stiffness with smaller subsidence providing stability of the motion segment. This fact is proved in ${ }^{14}$ where vertebroplasty with PMMA and $\mathrm{CaP}$ cement was compared for healthy and osteoporotic vertebrae by axial compressive test. The main conclusion was that the strength and stiffness of vertebrae was inversely correlated to the bone mineral density. The lower the initial BMD was, the more pronounced the augmentation effect was. Both type of cement augmentation reliably and significantly raised the stiffness and maximal tolerable force until failure in osteoporotic vertebral bodies. In non-porotic specimens, no significant increase was achieved. This may be the reason of the inverse correlation between failure load and bone quality of PEEK and PMMA spacers (Figure 3), but not only for the failure load but for the compressive stiffness and central compressive stresses as well (Figures 5 and 6 ).

Similarly to the load bearing, while in the PEEK group the stiffness is proportionate to the bone quality, in the PMMA group the weaker bone provides larger stiffness (Figure 5 and Table 5). Even for this, however, it seems to be surprising that the segmental shortenings are practically independent of bone quality in both groups (Figure 4 and Table 4). For PMMA group it can be acceptable since in this group the dominant factor is the cement penetration into the weaker bone, moreover, the shortening of segment depends also on the position of more or less irregularly formed cement cage. In PEEK group the reason may be the local failure, the knifeeffect of the edge of the spacer. The mode of trabecular failure could be a shear failure of horizontal struts under the edge of the spacer that yields buckling of relating longer vertical columns due to the loss of horizontal supports. ${ }^{5}$ This local zone of trabecular failure leads to the larger implant subsidence independently on the global bone quality.

Similarly to the bone quality, mainly contrasted are the relations of PEEK and PMMA devices with the vertebral cross sectional areas. While the failure load of PEEK group is strongly 
proportionate with the vertebral areas, the behaviour of the PMMA group shows an inverse relationship (Figure 7). Perhaps this fact is influenced also by the $30 \%$ difference of vertebral areas between the two groups. While in PMMA group the mean central and subcortical areas are 804 and $1137 \mathrm{~mm}^{2}$, in the PEEK groups they are 1068 and $1470 \mathrm{~mm}^{2}$, respectively (Table 1a), thus in PEEK group the areas are larger. However, the reason of the contrasting behaviour lies not on the areal differences, better on the different vertebra-device interface contact and structure ${ }^{5}$ and the different elastic-plastic behaviour between the two groups.

Strong positive correlation is between the cross sectional area and the deformability of PEEK group, while in PMMA group it is modestly negative (Figure 8). It is well known in mechanics that in the case of a homogeneous bar under compressive load, the cross sectional area is a part of the resistance against deformation. This is the case for the PMMA spacers, where the load transfer along the vertebra-device interface forms distributed load, consequently, the deformation is inversely proportionate to the vertebral area. The degree of correlation depends on the ratio of the total area and the contacting area between cement and vertebra. On the contrary, for PEEK spacers, the reason of the strong positive correlation is that the load transfer forms a quasi concentrated load along the vertebra-device interface. Consequently, the mechanical problem along the vertebra-device interface is not a simple compression one any more, better a bending problem. In this case, the mechanical fact for bent structures is manifested that a larger structure of the same material gives larger deformations for the same load, since the length of a bar or a plate are proportionate to the deformations but not to the resistance. If the load acts perfectly concentrated, this effect is even stronger. This leads to highly larger cage subsidence into the adjacent vertebrae for larger vertebral areas and endplates for PEEK spacers.

Surprisingly, similar tendency of correlation was found between the failure load and the vertebral areas in both groups (Figure 7). Previously we assumed for PMMA cement group, that the load bearing would be proportionate to the vertebral area. However, this is not the case. The modest negative correlation comes from the above detailed effect of concentrated-like load transfer along the vertebra-device interface. Namely, the failure load depends on the ratio of contacting cement area and total vertebral area, that is, on the extension of contact area between cement and endplates. If the cement covers the total endplate area, the behaviour of the vertebral-cement interface belongs to the pure compression problem. However, if the cement area covers only a part of the vertebral area, the load transfer along the interface moves from the distributed to the concentrated type load, consequently, the problem tends to the bending problems of larger subsidence. Since the cement/vertebra areal ratio is larger for smaller vertebrae resulting in higher load bearing, and inversely, that is why the failure load decreases with increasing vertebral area for an approximately constant contact area of cement cage. This fact was proved by compressive test $i^{5}$ by concluding that a relative larger indenter surface area on the same cross-sectional area of vertebra resulted in higher failure loads, or inversely, the same indenter area on larger vertebral area yields smaller failure loads. $\operatorname{In}^{11} 50-80 \%$, in ${ }^{12} 30-40 \%$ of vertebral body cross sectional area must be covered by the interbody device to prevent subsidence for moderate physiologic loads.

To explain the strong positive correlation of PEEK spacers between the load bearing and vertebral area is more complicated. First we checked the correlation between the bone quality and the vertebral area. Between CT-grey and vertebral area we have found no correlation at all, 
neither for superior and nor for inferior vertebrae, neither centrally and nor subcortically. Only a modest positive correlation $(\mathrm{R}=0,51)$ has been found between the BMD and the superior vertebral areas, both centrally $(R=0,49)$ and subcortically $(R=0,52)$. This has only a small part in the positive correlation between the load bearing and the vertebral areas. The real reason can be that the plastification with limited stresses and load bearing is localized into a small zone closed to the edges of PEEK spacer, while on the other large volume of vertebral bone the behaviour is still elastic with increasing stresses and load bearing. This fact can be seen in the typical loaddisplacement diagram of PEEK spacers, where the failure occurs just after the end of the elastic behaviour, without any longer plastification part of curve (Figure 1). Thus, the larger vertebral area of elastic zone provides higher failure load.

The relation between the elastic stiffnesses and the vertebral areas shows a modest positive correlation for both types of intervertebral devices, in line with the relations of failure loads and deformations detailed above. Since the elastic stiffness is practically the quotient of the elastic load and deformation, the modest correlation seem to be acceptable for PEEK spacers, where the failure happens soon after the elastic zone, without any longer global plastic zone, seen in the typical load-displacement diagram (Figure 1). However, in the case of PMMA cement cages there is a longer plastic zone before and after the failure, indicating global plastification, when the end of the elastic stiffness zone is farther from the failure. Global plastification needs larger volume. This is the reason that while the correlation of vertebral areas with both the failure load and failure deformations was modestly negative, for the elastic stiffness it was modestly positive for cement cages.

\section{Conclusion}

In line with previous studies, we concluded that the better contact between the shapes of device and bone is the clue to prevent complications coming from device subsidence. In osteoporotic spine instead of traditional PEEK spacers, PMMA cement spacers provide better contact and stronger vertebra-implant interface leading to enhanced stability of lumbar interbody fixation. In the case of PMMA cages, the failure deformation of segments is almost the half of that of the PEEK spacers, while the stiffness of them is two and a half times larger. The reason is the strong subsidence of PEEK spacers into the adjacent vertebrae. The weaker the vertebral bone is the larger subsidence occurs, in contrast to the cement spacers, where the bone quality has practically no importance. Moreover, we concluded that in strongly osteoporotic cases, the cement spacer provides larger strength. The nearly three times greater stiffness of cement spacers documented that the more perfect and smooth contact between the cement and endplate surface can prevent the extreme subsidence and disadvantageous stress distribution of lumbar interbody fixation. A more evenly distributed cement pattern results in greater increases in stiffness and induces smaller stress concentrations around the spacer, which may decrease the risk of subsidence.

In his study the novel PMMA cement cages and the standard PEEK spacers were compared with respect to severely osteoporotic cases, by using uniaxial compressive test. The current study indicates that the novel method, using PMMA cement spacers results in improved vertebradevice interface properties in particular for osteoporotic patients. Thus, we can conclude that the reason of the mainly contradictory behaviour of the PEEK and PMMA spacers lies on the 
different vertebra-device interface and on the local and global plastification that will be soon introduced elsewhere, based on the relating CT- and specimen-specific finite element simulations.

\section{REFERENCES}

1. Jost B, Cripton PA, Lund T, et al.. Compressive strength of interbody cages in the lumbar spine: the effect of cage shape, posterior instrumentation and bone density. Eur Spine J, 1998;7(2):132-41.

2. Lim TH, Kwon $\mathrm{H}$, Jeon $\mathrm{CH}$, et al. Effect of endplate conditions and bone mineral density on the compressive strength of the graft-endplate interface in anterior cervical spine fusion. Spine, 2001;26(8):951-6.

3. Steffen T. Tsantrizos A. Aebi M. Effect of implant design and endplate preparation on the compressive strength of interbody fusion constructs. Spine, 2000;25(9):1077-84.

4. Grant JP, Oxland TR, Dvorak MF, et al. The effects of bone density and disc degeneration on the structural property distributions in the lower lumbar vertebral endplates. J Orthop Res, 2002;20(5):1115-20.

5. Tan JS, Bailey CS, Dvorak MF, Fisher CG, Oxland TR. Interbody Device Shape and size are important to strengthen the vertebra-implant interface, Spine, 2005;30(6),638-44.

6. Csakany T, Varga PP. Discoplasty in Cases of Degenerative Spine with Complications of Osteoporosis, 52nd Congress of the Hungarian Orthopaedic Society and Section Meeting of the Hungarian Society of Arthroscopy, Szolnok, Hungary, 2009 June 25-27.

7. Csákány T, Rónai M, György ZM, Varga PP. Bone Cement as Intervertebral Spacer in Thoracolumbar Stabilization of Aging Spine - Radiological and Clinical Results, Global Spine Congress, Barcelona, Spain, 2011 March 23-26.

8. Au AG, Aiyangar AK, Anderson PA, Ploeg H-L. A New Bone Surrogate Model for Testing Interbody Device Subsidence, Spine, 2011;36(16):1289-96.

9. Hollowell JP, Vollmer DG, Wilson CR, Pintar FA, Yoganandan N. Biomechanical analysis of thoracolumbar interbody constructs. How important is the endplate? Spine, 1996;21(9):1032-6.

10. Hasegawa K, Abe M, Washio T, Hara T. An experimental study on the interface strength between titanium mesh cage and vertebra in reference to vertebral bone mineral density. Spine, 2001;26(8): 957-63.

11. Closkey RF, Parsons JR, Lee KC, Blacksin MF, Zimmermann MC. Mechanics of interbody spinal fusion. Analysis of critical bone graft area. Spine, 1993;18:1011-15.

12. Gill K. Introduction to interbody fusion. In: Lin, M.P., Gill, K. (eds): Lumbar interbody fusion. Rockville, Aspen, Maryland, 1989 p. 3-7.

13. Hoshijima K, Nightingale RW, Yu JR, Richardson WJ, Harper KD, Yamamoto H, Myers BS. Strength and stability of posterior lumbar interbody fusion: Comparison of titanium fiber mesh implant and tricortical bone graft. Spine, 1997;22(11):1181-8.

14. Heini PF, Berlemann U, Kaufmann M, Lippuner K, Fankhauser C, van Landuyt P. Augmentation of mechanical properties in osteoporotic vertebral bones - a biomechanical investigation of vertebroplasty efficacy with different bone cements. Eur Spine J. 2001;10(2):164-71.

The authors gratefully acknowledge the Hungarian Scientific Research Fund OTKA for providing financial support in the frame of the grant $K$-075018. The authors are grateful to Lajos Borbás and Gábor Szebényi for their help in laboratory experiments. 